\title{
A randomized control study to compare the efficacy of intranasal fluticasone propionate and intranasal budesonide in controlling postoperative symptoms in patients with nasal polyposis after endoscopic sinus surgery
}

\author{
Kiruba Shankar', Satvinder Singh Bakshi², Sunil Kumar Saxena ${ }^{3}$, Suriyanarayanan \\ Gopalakrishnan ${ }^{4}$
}

${ }^{1}$ Department of ENT and Head \& Neck Surgery, A.C.S Medical College, Vellappanchavadi, Chennai, India ${ }^{2}$ Department of ENT and Head \& Neck Surgery, All Indian Institute of Medical Sciences Mangalagiri, Guntur, Andhra Pradesh, India

${ }^{3}$ Department of ENT and Head \& Neck Surgery, JIPMER, Pondicherry, India

${ }^{4}$ Department of ENT and Head \& Neck Surgery, Mahatma Gandhi Medical College and Research Institute, Sri Balaji Vidyapeeth, Pillaiyarkuppam, Pondicherry, India

\section{ABSTRACT}

BACKGROUND. Sinonasal polyposis represents a chronic inflammatory condition characterized by nasal obstruction, reduction in the sense of smell and impaired quality of life. Intranasal steroids play an important role in preventing the postoperative recurrences in these cases. We carried out a study to evaluate and compare intra nasal budesonide and intranasal fluticasone propionate in the postoperative management of ethmoidal nasal polyposis.

MATERIAL AND METHODS. 106 patients with ethmoidal polyposis were treated with endoscopic polypectomy and were postoperatively started and maintained on intranasal steroids. 54 patients were managed with budesonide and 52 patients maintained on fluticasone propionate nasal spray. The patients were followed-up for 6 months and recurrences and control of symptoms evaluated.

RESULTS. There was a statistical difference in the SNOT-22 ( $\mathrm{p}<0.0001)$ and Lund-Kennedy scores $(\mathrm{p}=0.015)$ between patients using fluticasone propionate as compared to those using budesonide intra nasal spray by the end of the 6th month.

CONCLUSION. Both intranasal budesonide and fluticasone propionate are effective in controlling symptoms after endoscopic sinus surgery in patients with sinonasal polyposis; however, intranasal fluticasone propionate was more efficacious than budesonide in the control of postoperative symptoms.

KEYWORDS: nasal polyps, intranasal steroids, fluticasone propionate, budesonide.

\section{INTRODUCTION}

Sinonasal polyposis represents a chronic inflammatory condition of the nose and sinuses. The characteristic features include nasal obstruction, anosmia or hyposmia and impaired quality of life. The initial approach is medical management, most commonly with steroids ${ }^{1,2}$.

However, patients not responding to maximal medical treatment often undergo endoscopic sinus surgery. Systemic steroid therapy gives good results, but it is associated with a number of side effects like deranged sugar and lipid profile, peptic ulcers, etc. Intranasal steroids, on the other hand, act locally and are relatively free for these systemic side effects $^{3,4}$. Intranasal corticosteroid therapy has been proven to decrease the size of the polyps and reduce recurrence rate postoperatively. In a review, Aouad and Chiu acknowledge the advantage of topical medication in preventing polyp reformation and

Corresponding author: Dr. Satvinder Singh Bakshi, Associate professor of ENT, Department of ENT and Head \& Neck Surgery, All India Institute of Medical Sciences Mangalagiri, Guntur, Andhra Pradesh 522503, India 
highlight their use as the mainstay of therapy ${ }^{5}$. Other studies have analysed the role of topical steroid therapy in the management of nasal polyposis ${ }^{6}$.

A variety of formulations are available, each having its own safety profile and clinical efficacy. There is no consensus as to which the intranasal spray is the most effective in managing the symptoms postoperatively in patients with nasal polyps. The most commonly used intranasal sprays are budesonide and fluticasone propionate and hence a study comparing the efficacy of both these formulations in postoperative symptom control in patients with nasal polyposis was planned.

\section{MATERIAL AND METHODS}

The study protocol was reviewed and approved by the Department of Otolaryngology and by the Ethical Committee of our Institute. The treatment procedures were explained in full details to the study participants and a written informed consent was obtained from all patients.

Patients willing to have surgery, aged 18 years and above, attending the ENT outpatient department of our Institute with bilateral nasal polyposis, were considered for the study. Patients with gross septal deviation, suspected sinonasal malignancy, history of nasal surgery, invasive fungal disease, uncontrolled diabetes or hypertension, patients on oral or inhaled steroids for other medical conditions were excluded from the study.

All patients underwent history taking, general and thorough otorhinolaryngological examination, which included anterior rhinoscopy for the evaluation of the nasal polyps, posterior rhinoscopy and nasal endoscopy with 'Karl Storz endoscope' - using 'Hopkins Telescopes': $0^{\circ}$ (straight forward), $30^{\circ}$ (forward oblique) and $70^{\circ}$ (lateral) scopes. The LundMackay scoring system was used for assessing the severity on the CT scan. All the patients underwent nasal endoscopy at each postoperative visit and were scored with the Lund-Kennedy scoring system. The symptoms were evaluated pre and post procedure using the Sino-nasal outcome test scores (SNOT-22).

\section{Surgical procedure}

All patients were admitted a day before and were operated under general anaesthesia in the operation theatre. The nose was prepared with cotton pledgets soaked in 4\% topical lidocaine with 1:1000 adrenaline, introduced in the inferior meatus and middle meatus and left for 5-10 minutes. This helped achieve anaesthesia as well as vasoconstriction.

Local infiltration with 2\% lidocaine with 1:200000 adrenaline was injected into the uncinate process, along the floor of nasal cavity near the greater palatine foramen, anterior middle turbinate, ethmoidal bulla and to the polyps themselves up to $4-5 \mathrm{~m} 1$ in total. The patient was placed in supine position on the operating table with 15-degree head elevation. A zero-degree $4 \mathrm{~mm}$ Hopkins Rod was used for most of the surgery except for visualizing the maxillary ostia when a 30-degree or 70-degree scope was used. The anterior attachment of the uncinate process was incised to perform the infundibulotomy. The Freer's elevator was used to elevate the uncinate process and the ethmoidal bulla was opened using the straight Blakesley-Wilde forceps. The polyps were avulsed using the straight and up cutting forceps till most of the polyps were removed.

The posterior ethmoids were entered and all the polyps removed. The sphenoid was approached via the posterior ethmoid. The natural ostium of the maxillary sinus was then entered by using a blunt probe. Anterior nasal packing was done with acriflavine-liquid paraffin pack.

\section{Postoperative care}

All patients were started on oral antibiotics (Amoxicillin with Clavulanic acid or Ciprofloxacin for penicillin sensitive cases), analgesics and antihistamines for three days. The anterior nasal packing was removed under supervision 24 hours after the surgery and nasal wash with warm saline solution was given 24 hours after pack removal. The patients were discharged on the $2^{\text {nd }}$ postoperative day with the advice to continue topical nasal decongestants $(0.1 \%$ ephedrine nasal drops) twice a day for 5 days.

\section{Assignment to treatment groups}

The patients assigned to either of the two groups: treatment group A or the group B by the method of block randomization. In the treatment group A patients were advised budesonide nasal spray at a dose of $128 \mathrm{mcg}$ per day and in the treatment group B the patients were advised fluticasone propionate nasal spray at a dose of $200 \mathrm{mcg}$ per day. The patients were asked to maintain a diary of the medications in order to ensure compliance.

\section{Follow-up}

Outcomes were recorded and evaluated pre and post procedure using the Sino-nasal outcome test score (SNOT-22) at 1, 3 and 6-month interval by a blinded investigator to reduce the bias. The results were analysed at the end of the study by another blinded investigator. The SNOT-22 score was initially developed in 1998 and included 16 items, which were later increased to 22. The score consists of 22 items graded in 6 levels ( 0 for no problem, 5 for the worst possible symptom). The score ranges from 0 to 110 and is obtained by adding individual scores for each item. It is a validated questionnaire for the assessment of the quality of life in patients with sinonasal disease and has a specific advan- 
Table 1

Comparison of patient demographics and preoperative Lund-Mackay scores between the groups.

\begin{tabular}{cccc}
\hline Parameter & $\begin{array}{c}\text { Group A } \\
\mathbf{n}=\mathbf{5 4}\end{array}$ & $\begin{array}{c}\text { Group B } \\
\mathbf{n = 5 2}\end{array}$ & Pvalue \\
\hline Age (Mean \pm SD) & $32.6 \pm 8.2$ & $33.1 \pm 11.6$ & 0.797 \\
\hline Sex & & & \\
\hline Male & 25 & 28 & 0.776 \\
\hline Female & 29 & 24 & \\
\hline Pre op Lund-Mackay score (Mean \pm SD) & $19.2 \pm 1.6$ & $18.8 \pm 2.3$ & 0.802 \\
\hline
\end{tabular}

tage of evaluating the impact of treatment outcomes.

In addition, nasal endoscopy was done at each visit and findings documented as per the Lund-Kennedy scoring system. The Lund-Kennedy scoring system takes into account 3 parameters which include the presence of polyps, edema and secretions, scored 0 to 2. Each nasal cavity is scored separately and the total score ranges from 0 to 12 .

\section{Statistical analysis}

Statistical analysis was done using the SPSS software ver. 21 (IBM Co., Armonk, NY, USA). All quantitative variables were estimated using mean, median and standard deviation [SD].

The SNOT-22 scores were analysed using the independent t-test and one-way ANOVA test. The chi square test was used for comparisons of the gender distribution of the groups. $\mathrm{p}<0.05$ was considered as statistically significant.

\section{RESULTS}

60 patients were taken in each group. However, 6 patients in group A and 8 patients in group B were lost to follow-up. Therefore, the sample size in group A became 54 and in group B 52.

\section{Patient population}

No statistically significant differences were found between groups in terms of age $(32.6 \pm 8.2$ and $33.1 \pm 11.6, p=0.797)$ and gender (29 females and 25 males, 24 females and 28 males, respectively) $(p=0.776)$. A summary of the patient demographics is given in Table 1.

There was no difference in the preoperative LundMackay CT scan scores between the groups $(19.2 \pm 1.6$ and 18.8 \pm 2.3$)(p=0.802)$.

\section{SNOT-22 score}

The mean baseline SNOT-22 score in group A was $56.28 \pm 5.44$ and in group B was 54.74 \pm 7.60 . There was no statistical difference between the baseline scores of both groups $(p=0.2317)$ (Table 2$)$.

In group $\mathrm{A}$ the SNOT-22 score reduced from $56.28 \pm 5.44$ to $18.90 \pm 1.15(p<0.0001)$. In group B the SNOT-22 score reduced from $54.74 \pm 7.60$ to $10.43 \pm 1.32(p<0.0001)$.

The analysis of the SNOT-22 scores between the two groups was done at 1, 3 and 6 months. It was seen that there was no difference between the SNOT-22 scores at the $1^{\text {st }}$ month follow-up $(p=0.2975)$. However, there

Table 2

Comparison of SNOT-22 scores between both groups.

\begin{tabular}{cccc}
\hline & $\begin{array}{c}\text { Group A } \\
\mathbf{n}=\mathbf{5 4}\end{array}$ & $\begin{array}{c}\text { Group B } \\
\mathbf{n}=\mathbf{5 2}\end{array}$ & $\boldsymbol{P}$ \\
\hline Preoperative & $56.28 \pm 5.44$ & $54.74 \pm 7.60$ & 0.231 \\
\hline $1^{\text {st }}$ month & $38.44 \pm 2.27$ & $37.97 \pm 2.76$ & 0.297 \\
\hline $3^{\text {rd }}$ month & $21.76 \pm 1.93$ & $15.61 \pm 2.54$ & $<\mathbf{0 . 0 0 0 1}$ \\
\hline $6^{\text {th }}$ month & $18.90 \pm 1.15$ & $10.43 \pm 1.32$ & $<\mathbf{0 . 0 0 0 1}$ \\
\hline $\boldsymbol{P}$ & $<\mathbf{0 . 0 0 0 1}$ & $<\mathbf{0 . 0 0 0 1}$ & \\
\hline
\end{tabular}


was a significant difference in the SNOT-22 scores in the fluticasone propionate group as compared to the budesonide group at the $3^{\text {rd }}(p<0.0001)$ and $6^{\text {th }}$ month postoperatively $(p<0.0001)$ (Table 2$)$.

\section{Lund-Kennedy endoscopic scores}

The scores are shown in Table 3. It was seen that there was a statistical reduction in scores following surgery in each group and this was maintained till the end of the 6-month follow-up. There was no statistical difference in the scores between the groups pre-operatively and till the $3^{\text {rd }}$ post-op month. However, by the end of 6 months the difference between the fluticasone propionate group as compared to the budesonide group was statistically significant $(p=0.015)$.

\section{DISCUSSIONS}

The role of corticosteroids in the management of nasal polyposis is well established ${ }^{7}$. However, the benefits of systemic corticosteroids are overshadowed by their undesirable systemic effects; hence topical application, with its safety profile and easy applicability becomes an increasing beneficial option ${ }^{8,9}$. Several studies have evaluated intranasal steroids in nasal polyposis. They demonstrate a decrease in the size of polyps, improvement in symptoms, and improvement in the nasal peak inspiratory flow rate ${ }^{10,11}$.

The budesonide therapy has been evaluated in previous studies for controlling recurrence after polypectomy and has been found to be beneficial ${ }^{12}$. In addition, various formulations like inhalers, respules ${ }^{13}$ and irrigations ${ }^{14}$ have been tried in order to deliver a higher concentration of the drug intranasally and reduce systemic absorption; however, there is a paucity of evidence since only a few studies have been conducted. Fluticasone is a relatively newer generation corticosteroid with more tolerability and lesser systemic absorption. Its usage in allergic rhinitis and nasal polyps is well established ${ }^{15,16}$.
In our study, both the fluticasone and budesonide group showed a statistical improvement in the SNOT22 and Lund-Kennedy scores, proving their clinical efficacy. Although both are beneficial, patients using fluticasone reported lower SNOT-22 and Lund-Kennedy scores as compared to those using budesonide. This difference became statistically significant by the $3^{\text {rd }}$ month in terms of SNOT-22 scores and by the $6^{\text {th }}$ month with respect to the Lund-Kennedy endoscopic scores.

Common local side effects of INSs include headache, dryness, nasal irritation, burning and epistaxis. In our study, the local side effects in both groups were nearly similar. None of the patients reported any incidence of epistaxis; however, one patient in the budesonide group complained of dryness and one patient in the fluticasone group complained of burning sensation; nevertheless, these complaints were not significant enough for changing the drug in these patients. There is also concern regarding nasal mucosal atrophy, but long-term studies with fluticasone propionate did not identify indications of atrophy ${ }^{17}$.

There are several limitations to our study, the most important being the modest sample size and the lack of a tool to measure and ensure patient compliance. In addition, it is also possible that patients may have used other therapies like saline irrigations, which can affect the action of topical intranasal steroids and influence the outcome. Other delivery methods like steroid nasal irrigations could have also been compared, especially in the case of budesonide. Also, there is no consensus on how long the intranasal steroids should be given postoperatively and long-term studies need to be planned in this regard.

\section{CONCLUSIONS}

The mainstay therapy following endoscopic sinus surgery for nasal polyps are intranasal steroids. A variety of formulations are available. In our study, we found fluticasone propionate nasal spray to be more

Table 3

Comparison of Lund-Kennedy endoscopic scores between both groups.

\begin{tabular}{cccc}
\hline & $\begin{array}{c}\text { Group A } \\
\mathbf{n}=\mathbf{5 4}\end{array}$ & $\begin{array}{c}\text { Group B } \\
\mathbf{n}=\mathbf{5 2}\end{array}$ & $\boldsymbol{P}$ \\
\hline Preoperative & $9.43 \pm 2.46$ & $9.54 \pm 1.81$ & 0.794 \\
\hline $1^{\text {st }}$ month & $3.82 \pm 1.16$ & $3.64 \pm 1.02$ & 0.373 \\
\hline $3^{\text {rd }}$ month & $2.33 \pm 1.06$ & $2.14 \pm 1.09$ & 0.365 \\
\hline $6^{\text {th }}$ month & $2.54 \pm 1.11$ & $2.02 \pm 1.04$ & $\mathbf{0 . 0 1 5}$ \\
\hline $\boldsymbol{P}$ & $<\mathbf{0 . 0 0 0 1}$ & $<\mathbf{0 . 0 0 0 1}$ & \\
\hline
\end{tabular}


effective as compared to budesonide nasal spray in reducing the SNOT-22 and Lund-Kennedy scores. This reduction in symptoms was seen till 6 months postoperatively. Further long-term studies are required to evaluate the efficacy and safety of fluticasone over budesonide in patients with nasal polyposis.

Conflict of interest: The authors declare that there is no conflict of interest.

Contribution of authors: All authors have equally contributed to this work.

\section{REFERENCE}

1. Seiberling KA, Kidd SC, Kim GH, Church CA. Efficacy of dexamethasone versus fluticasone nasal sprays in postoperative patients with chronic rhinosinusitis with nasal polyps. Am J Rhinol Allergy. 2019;33(5):478-82. DOI: 10.1177/1945892419841355. Epub 2019 Apr 16.

2. Vaidyanathan S, Barnes M, Williamson P, Hopkinson P, Donnan PT, Lipworth B. Treatment of chronic rhinosinusitis with nasal polyposis with oral steroids followed by topical steroids: a randomized trial. Ann Intern Med. 2011;154(5):293-302. DOI: 10.7326/0003-4819-154-5-20110301000003.

3. Bensch GW. Safety of intranasal corticosteroids. Ann Allergy Asthma Immunol. 2016;117(6):601-5. DOI: 10.1016/j.anai.2016.06.009.

4. Blaiss MS. Safety considerations of intranasal corticosteroids for the treatment of allergic rhinitis. Allergy Asthma Proc. 2007;28(2):145-52.

5. Aouad RK, Chiu AG. State of the art treatment of nasal polyposis. Am J Rhinol Allergy. 2011;25(5):291-8. DOI: 10.2500/ajra.2011.25.3681.

6. Fokkens WJ, Lund VJ, Mullol J, Bachert C, Alobid I, Baroody F, et al. EPOS 2012: European position paper on rhinosinusitis and nasal polyps 2012. A summary for otorhinolaryngologists. Rhinology. 2012;50(1):1-12. DOI: $10.4193 /$ Rhino50E2.

7. Fandiño M, Macdonald KI, Lee J, Witterick IJ. The use of postoperative topical corticosteroids in chronic rhinosinusitis with nasal polyps: a systematic review and meta-analysis. Am J Rhinol Allergy. 2013;27(5):e146-
57. DOI: 10.2500/ajra.2013.27.3950.

8. Demoly P. Safety of intranasal corticosteroids in acute rhinosinusitis. Am J Otolaryngol. 2008;29(6):403-13. DOI: 10.1016/j.amjoto.2007.11.004. Epub 2008 Jun 16.

9. Derendorf H, Meltzer EO. Molecular and clinical pharmacology of intranasal corticosteroids: clinical and therapeutic implications. Allergy. 2008;63(10):1292-300. DOI: 10.1111/j.1398-9995.2008.01750.x.

10. Joe SA, Thambi R, Huang J. A systematic review of the use of intranasal steroids in the treatment of chronic rhinosinusitis. Otolaryngol Head Neck Surg. 2008;139(3):340-7. DOI: 10.1016/j.otohns.2008.05.628.

11. Rudmik L, Schlosser RJ, Smith TL, Soler ZM. Impact of topical nasal steroid therapy on symptoms of nasal polyposis: a meta-analysis. Laryngoscope. 2012;122(7):1431-7. DOI: 10.1002/lary.23259. Epub 2012 Mar 12.

12. Johansson L, Holmberg K, Melén I, Stierna P, Bende M. Sensitivity of a new grading system for studying nasal polyps with the potential to detect early changes in polyp size after treatment with a topical corticosteroid (budesonide). Acta Otolaryngol. 2002;122(1):49-53.

13. Neubauer PD, Schwam ZG, Manes RP. Comparison of intranasal fluticasone spray, budesonide atomizer, and budesonide respules in patients with chronic rhinosinusitis with polyposis after endoscopic sinus surgery. Int Forum Allergy Rhinol. 2016;6(3):233-7. DOI: 10.1002/alr.21688. Epub 2015 Dec 17.

14. Huang ZZ, Chen XZ, Huang JC, Wang ZY, Li X, Chen XH, et al. Budesonide nasal irrigation improved Lund-Kennedy endoscopic score of chronic rhinosinusitis patients after endoscopic sinus surgery. Eur Arch Otorhinolaryngol. 2019;276(5):1397-1403. DOI: 10.1007/s00405019-05327-6. Epub 2019 Feb 20.

15. Holmberg K, Juliusson S, Balder B, Smith DL, Richards DH, Karlsson G. Fluticasone propionate aqueous nasal spray in the treatment of nasal polyposis. Ann Allergy Asthma Immunol. 1997;78(3):270-6.

16. Vlckova I, Navrátil P, Kana R, Pavlicek P, Chrbolka P, Djupesland PG. Effective treatment of mild-to-moderate nasal polyposis with fluticasone delivered by a novel device. Rhinology. 2009;47(4):419-26. DOI: 10.4193/ Rhin09.024.

17. Holm AF, Fokkens WJ, Godthelp T, Mulder PG, Vroom TM, Rijntjes E. A 1-year placebo-controlled study of intranasal fluticasone propionate aqueous nasal spray in patients with perennial allergic rhinitis: a safety and biopsy study. Clin Otolaryngol Allied Sci. 1998;23(1):69-73. 